\title{
Towards Macromolecular Architectures of Corannulene
}

\author{
Mihaiela C. Stuparu*
}

\begin{abstract}
In an attempt to introduce corannulene chemistry to macromolecular science, my research program is dedicated to synthetic strategies leading to corannulene-based polymers with interesting architectures and properties. In this brief account, I will discuss the synthesis of a variety of corannulene-based building blocks (monomers) and their utility in the preparation of a wide range of corannulene-rich macromolecular structures.
\end{abstract}

Keywords: Conjugated polymers · Corannulenes · Dendrimers · Optoelectronic materials · Polymer synthesis

\section{Introduction}

Today, as a society, we are facing many problems. The energy crisis is just one of them. ${ }^{[1]}$ In this regard, among many other alternatives, capturing solar radiation and transforming it into useful forms of energy is an appealing idea that has captivated the minds of many scientists. The result of this research is a wide variety of photovoltaic devices including organic solar cells. ${ }^{[2,3]}$ The most efficient organic solar cells are based on the donor-acceptor hetero-junction structure. ${ }^{[4-6]}$ In this solar cell, a photoactive organic layer is sandwiched between a cathode and an anode. The active layer is composed of an electron-donating and an electron-accepting organic semiconductor material deposited either as a bilayer or a blended structure. Upon light absorption, electron-hole pairs are created within the active layer. Subsequently, the holes are transported to the anode - with the assistance of the built-in electric field present between the two electrodes - through the donor material while the electrons are transported to the cathode through the acceptor material. In this way, a photocurrent is generated. Conjugated polymers ${ }^{[7-9]}$ such as

\footnotetext{
$\overline{{ }^{*} \text { Correspondence: }}$ Dr. M. C. Stuparu Institute of Organic Chemistry

University of Zurich

Winterthurerstr. 190

$\mathrm{CH}-8092$ Zürich

Tel.: +41446353954

E-mail: stuparu@oci.uzh.ch
}

poly(phenylene vinylene)s, poly(fluorene) s, poly-(para phenylene)s, poly(thiophene) $\mathrm{s}$, and countless other varieties of conjugated polymers are used as electron-donating materials. Interestingly, very little effort has been devoted to identifying new acceptor molecules/polymers ${ }^{[4,10]}$ and fullerene $\mathrm{C}_{60}$ and its derivatives remain the most utilized electron accepting material. ${ }^{[6,8]}$

In 2008, I had the pleasure of working with Prof. Dr. H. K. Hall Jr. at the University of Arizona (Tucson). It is at Tucson that I learned about the synthesis of homopolymers and alternating copolymers by free radical polymerization methods. ${ }^{[11]}$ After a one-year position at Tucson, I joined the team of Prof. Siegel at University of Zurich, and it is there that I asked the question: Can I take the corannulene chemistry that is developed in Siegel laboratory and implement it in macromolecular science? Since corannulene is a known electron acceptor, ${ }^{[12,13]}$ will these corannulenebased polymers be good (n-type) materials for organic electronics applications? Furthermore, can corannulene polymers host fullerene $\mathrm{C}_{60}$ molecules by making supramolecular complexes via $\pi-\pi$ stacking interactions? ${ }^{[14-19]}$ With the support of Prof. Siegel and the Ambizione program (SNSF) these questions can be addressed and the initial results are presented within.

\section{Various Macromolecular Architectures}

In choosing corannulene as a basic building block for macromolecular synthesis, one can take advantage of the many attributes of this molecule: i) it is possible to prepare corannulene on kilogram scale; ${ }^{[20]}$ ii) one can install 1-5 substituents on the corannulene nucleus: ${ }^{[21-23]}$ iii) corannulene and its derivatives are soluble in a variety of common organic solvents.

\subsection{Corannulene Dendrimers}

Dendrimers are perfectly branched macromolecules with a globular structure and high number of surface functionalities. ${ }^{[24]}$ Hence, a variety of dendritic structures have been prepared with interest towards opto-electronic applications. ${ }^{[25]}$ In this context, corannulene represents an ideal dendritic core with a high density of branching points spread in a five-fold symmetric $\left(C_{5}\right)$ fashion (Scheme 1). ${ }^{[26]}$ Initially, we targeted the synthesis of dendrimer $\mathbf{3}$ having a corannulene-triazole alternating structure via Sharpless ${ }^{[27]}$ and Meldal[28] variations of the Huisgen reaction. We chose this particular coupling reaction for two reasons; i) the known high efficiency of the reaction that is necessary to build dendrimers via step-wise synthesis, and ii) a range of interesting structural and electronic features that the resulting 1,2,3-triazole moiety presents. For example, the five-membered heterocyclic ring displays a strong dipole moment and is capable of forming $\pi-\pi$ interactions, while the nitrogen atoms are available for metal-ion coordination and hydrogen bonding interactions. ${ }^{[29]}$ Unfortunately, to date, all attempts to produce our initial penta-substituted dendrimer $\mathbf{3}$ have failed. However, replacing the aromatic acetylenes with alkyl acetylenes and introducing a linker between the acetylene and the corannulene core resulted in good yields of penta-substituted dendrimer 5. It is clear that by modifying electronic structure and steric factors, one can now hope for the synthesis of a higher generation dendrimer such as $\mathbf{6}$.

\subsection{Corannulene-core Star Polymers}

Star polymers are branched polymeric materials in which the branches emanate from a central core. ${ }^{[30]}$ Interest in star polymers originates from their novel properties that are inaccessible in linear polymers. For instance, star polymers exhibit improved 
solubility due to multiple end groups and low viscosity due to branched architecture when compared to linear polymers of similar composition.
The five-fold $\left(C_{5}\right)$ symmetry of the corannulene molecule presents a unique core for synthesis of star polymers. Initially, a corannulene derivative featuring five hy-

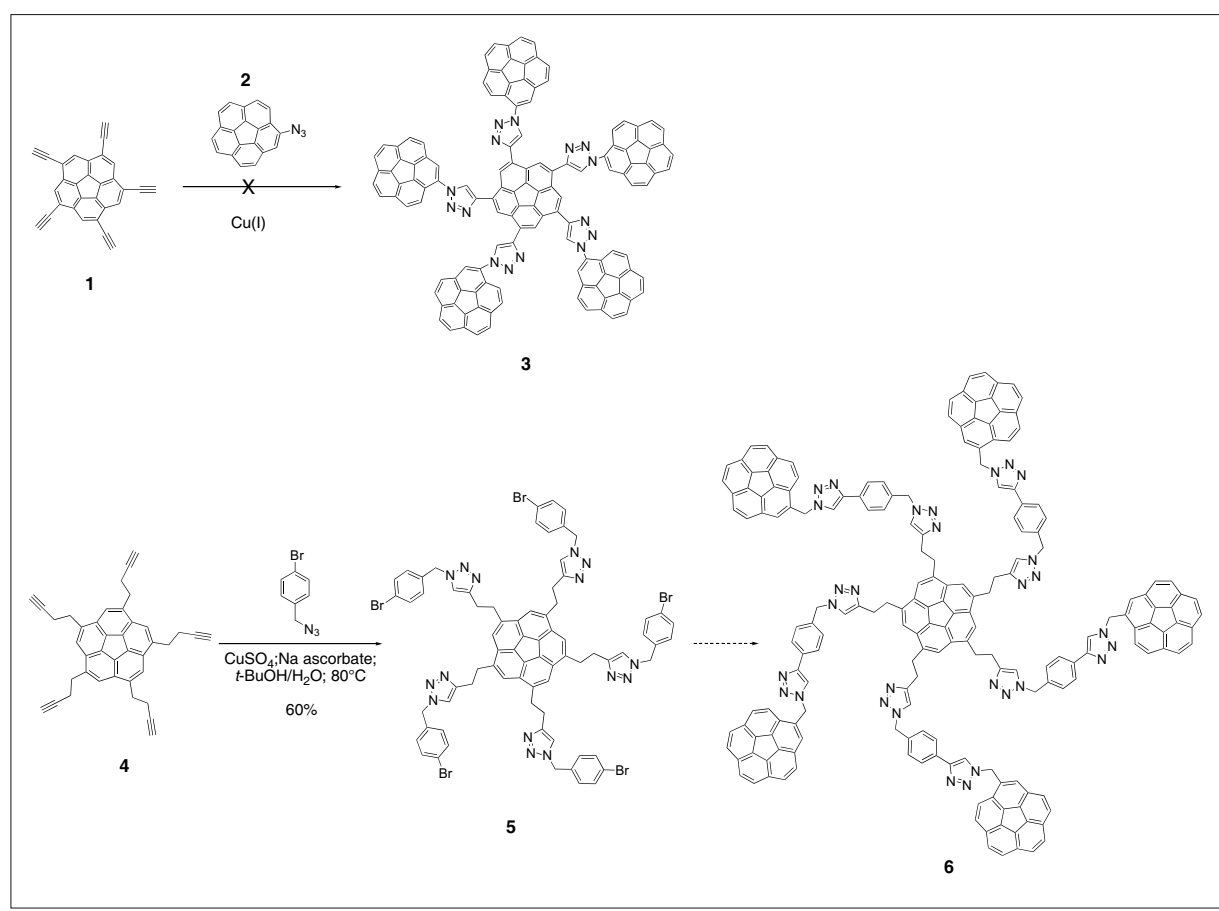

Scheme 1.

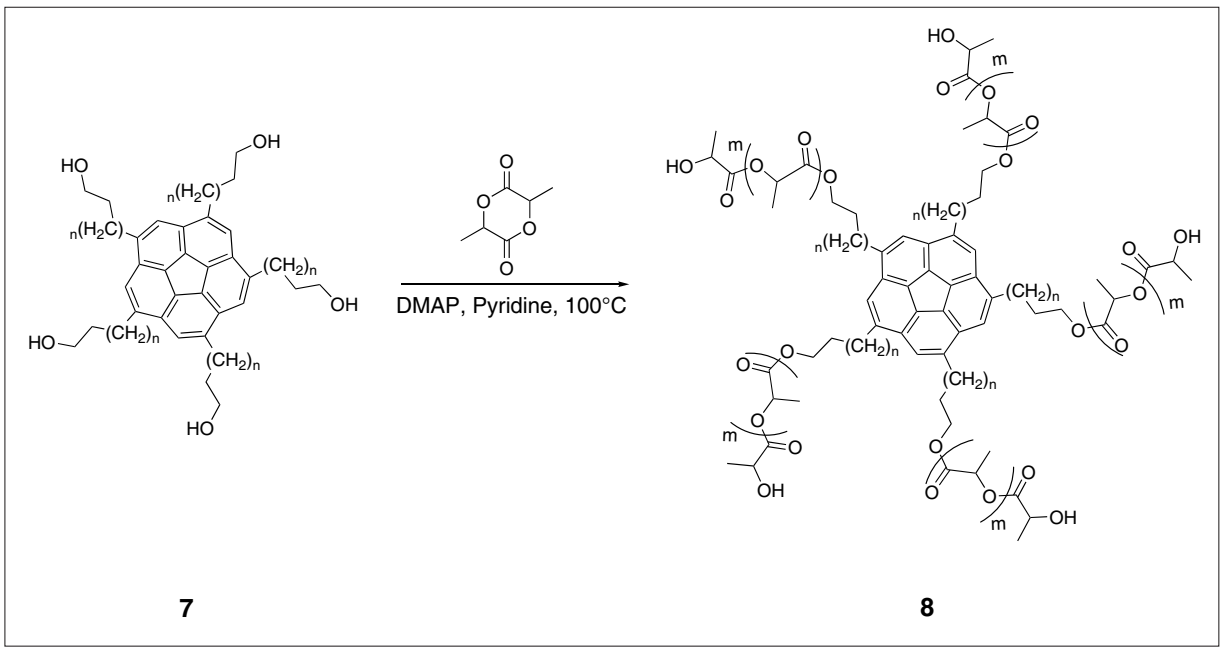

Scheme 2 .

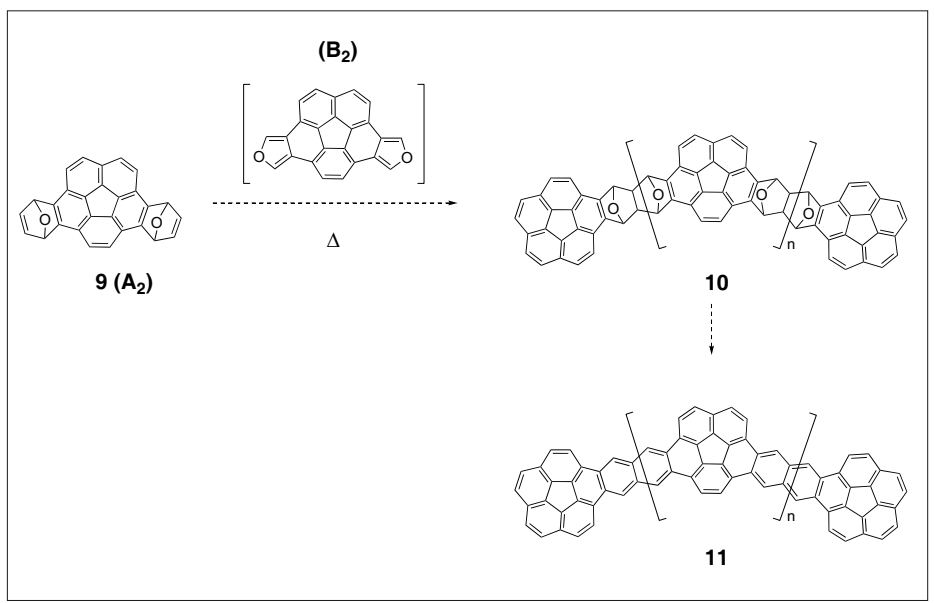

droxyl groups is synthesized (Scheme 2). Each hydroxyl group in this core molecule can act as an initiator for ring-opening polymerization of lactide monomer in a controlled fashion. ${ }^{[31]}$ In this way, a variety of five-arm star polylactides have been prepared by changing the ratio of the lactide monomer to the core initiator molecule 7. Synthetic access to polymer $\mathbf{8}$ has now opened up a way to study their properties. We anticipate that these polymers will selfassemble into columnar structures (under appropriate conditions) in which the polymer chains will create a shell around the stacked core molecule.

\subsection{Corannulene Main-chain Polymers}

Many synthetic approaches can be envisaged that would lead to polymers containing corannulenes in the polymer backbone. For example, Diels-Alder polyaddition $^{[32,33]}$ between $\mathrm{A}_{2}$ and $\mathrm{B}_{2}$ type monomers (Scheme 3 ) can give rise to main-chain corannulene polymers with a double-stranded structure. ${ }^{[32,34]}$ However, preparation of these polymers will be synthetically challenging, as suitable monomers have to be synthesized from corannulenes. Furthermore, to obtain an appreciable molar mass of the polymer, the reaction conditions and solubility of the growing polymeric chains will have to be meticulously optimized. This challenge, however, is worth taking as the new polymers may exhibit some very interesting physical and optical properties. At the moment, we are focusing on the synthesis of discrete oligomers rather than polymers so as to understand the reactivity of the components, optimize reaction conditions, and fully investigate the properties of the resulting structures.[35]

As another approach, palladium-catalyzed Sonogashira-Hagihara coupling between an aryl-alkyne and an aryl-halide can also be used for polymer synthesis (Scheme 4).[36] This is a promising route especially as a variety of alkyne-substituted corannulenes have been synthesized by our group..$^{[21,37]}$

Scheme 3

\subsection{Corannulene Side-chain Polymers}

Unlike main-chain polymers, sidechain polymers will be electronically nonconjugated. However, depending upon the flexibility of the pendent, these macromolecules may show liquid crystalline properties with an ordered and rigid corannulene array surrounding the soft and flexible polymer backbone (Scheme 5). Initial results show that one can indeed prepare acrylate-based monomers on a gram scale. More importantly, these monomers can be polymerized via free radical polymerization to give high molecular weight (100 


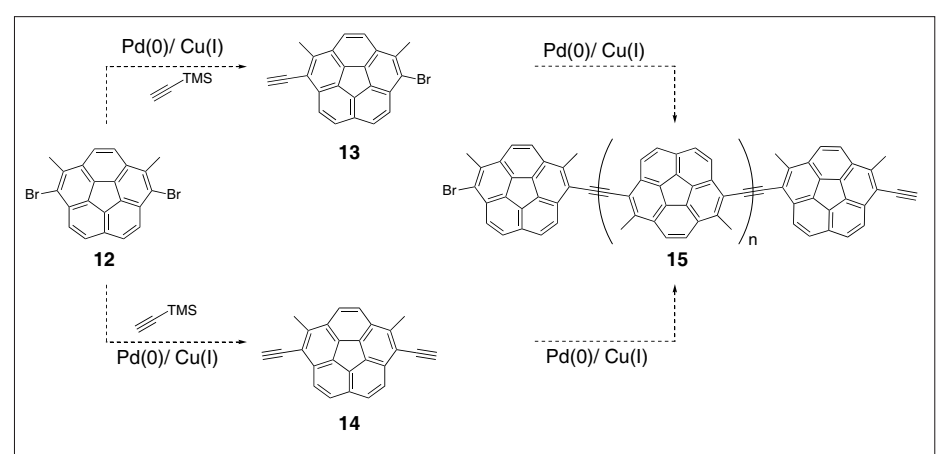

Scheme 4.

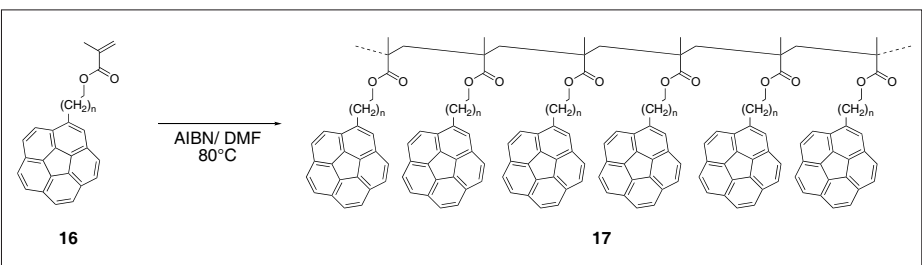

Scheme 5 .

$\mathrm{kDa}$ ) polymers carrying corannulene moieties as a side group on each repeat unit. Access to these materials now gives us an opportunity to investigate their properties.

\section{Conclusion}

In summary, we are trying to design a variety of synthetic strategies that will give access to a range of high molecular weight corannulene polymers of various architectures. Initial results suggest that the necessary building blocks based on corannulene structures can be synthesized. Furthermore, in some cases high molecular weight polymers can be obtained whereas in other cases discrete oligomers can be synthesized. Progress so far has been encouraging and the future is full of promise.

Received: August 22, 2011
[1] N. Armaroli, V. Balzani, Angew. Chem., Int. Ed. 2007, 46, 52 .

[2] C. W. Tang, Appl. Phys. Lett. 1986, 48, 183.

[3] C. J. Brabec, N. S. Sariciftci, J. C. Hummelen, Adv. Funct. Mater. 2001, 11, 15.

[4] J. Xue, Polym. Rev. 2010, 50, 411

[5] S. Günes, H. Neugebauer, N. S. Sariciftci, Chem. Rev. 2007, 107, 1324.

[6] B. C. Thompson, J. M. J. Fréchet, Angew. Chem., Int. Ed. 2008, 47, 58.

[7] J. Chen, Y. Cao, Acc. Chem. Res. 2009, 42, 1709.

[8] L.-M. Chen, Z. Hong, G. Li, Y. Yang, $A d v$. Mater. 2009, 21, 1434.

[9] F. G. Brunetti, R. Kumar, F. Wudl, J. Mater. Chem. 2010, 20, 2934.

[10] P. Sonar, J. P. Fong Lim, K. L. Chan, Energy Environ. Sci. 2011, 4, 1558.

[11] M. C. Stuparu, J. Xu, H. K. Hall Jr, Tetrahedron Lett. 2009, 50, 6743.

[12] A. Ayalon, M. Rabinovitz, P. C. Cheng, L. T. Scott, Angew. Chem. 1992, 104, 1691.

[13] D. Eisenberg, J. M. Quimby, E. A. Jackson, L. T. Scott, R. Shenhar, Chem. Commun. 2010, 46, 9010.

[14] R. Maag, B. Northrop, A. Butterfield, A. Linden, O. Zerbe, Y. Lee, K. Chi, P. Stang, J. S. Siegel, Org. Biomol. Chem. 2009, 7, 4881.
[15] D. Bandera, K. K. Baldridge, A. Linden, R. Dorta, J. S. Siegel, Angew. Chem., Int. Ed. 2010, $50,865$.

[16] Y.-T. Wu, J. S. Siegel, Chem. Rev. 2006, 106, 4843.

[17] V. M. Tsefrikas, L. T. Scott, Chem. Rev. 2006 106, 4868.

[18] A. Sygula, Eur. J. Org. Chem. 2011, 9, 1611.

[19] A. Sygula, S. Saebø, Int. J. Quantum Chem. 2009, 109, 65

[20] A. Butterfield, J. S. Siegel, manuscript in preparation.

[21] Y.-T. Wu, D. Bandera, R. Maag, A. Linden, K K. Baldridge, J. S. Siegel, J. Am. Chem. Soc. 2008, 130, 10729 .

[22] G. Xu, A. Sygula, Z. Marcinow, P. Rabideau, Tetrahedron Lett. 2000, 41, 9931.

[23] A. Ueda, S. Nishida, K. Fukui, T. Ise, D Shiomi, K. Sato, T. Takui, K. Nakasuji, Y. Morita, Angew. Chem., Int. Ed. 2010, 49, 1678.

[24] B. M. Rosen, C. J. Wilson, D. A. Wilson, M. Peterca, M. R. Imam, V. Percec, Chem. Rev. 2009, 109, 6275 .

[25] V. Balzani, P. Ceroni, M. Maestri, C. Saudan, V. Vicinelli, Top. Curr. Chem. 2003, 228, 159.

[26] D. Pappo, T. Mejuch, O. Reany, E. Solel, M Gurram, E. Keinan, Org. Lett. 2009, 11, 1063.

[27] H. C. Kolb, M. G. Finn, K. B. Sharpless, Angew. Chem., Int. Ed. 2001, 40, 2004.

[28] C. W. Tornoe, C. Christensen, M. Meldal, J. Org. Chem. 2002, 67, 3057.

[29] M. Juricek, P. H. J. Kouwer, A. E. Rowan, Chem. Comm. 2011, 47, 8740.

[30] N. Hadjichristidis, J. Polym. Sci. Part A: Polym. Chem. 1999, 37, 857.

[31] F. Nederberg, E. F. Connor, M. Möller, T. Glauser, J. L. Hedrick, Angew. Chem., Int. Ed. 2001, 113, 2784.

[32] A. D. Schlueter, Adv. Mater. 1991, 3, 282.

[33] G. W. Goodall, W. Hayes, Chem. Soc. Rev. 2006, 35, 280.

[34] U. Scherf, J. Mater. Chem. 1999, 9, 1853.

[35] F. Furrer, M. Stuparu, in preparation.

[36] Q. Zhou, T. M. Swager, J. Am. Chem. Soc. 1995, 117,12593

[37] T. Hayama, Y.-T. Wu, A. Linden, K. K. Baldridge, J. S. Siegel, J. Am. Chem. Soc. 2007, 129 , 12612 